\title{
STILL out of Breath?
}

\author{
Nicholas Robillard ${ }^{\mathrm{a}}$, Robert Wistaff ${ }^{\mathrm{a}}$, Maxime Lamarre-Cliche ${ }^{\mathrm{a}}$, \\ Paul Van Nguyen ${ }^{\mathrm{a}}$, Mikhael Laskine ${ }^{\mathrm{a}, \mathrm{b}}$
}

\begin{abstract}
Adult onset Still's disease (AOSD) is a rare inflammatory syndrome mostly seen in young adults. Known for its wide range of clinical manifestations, AOSD often presents with non-remitting systemic signs and symptoms. Many rare case associations have been described with AOSD, but only few with pulmonary hypertension $(\mathrm{PAH})$. We are presenting a sixth known case of a young female adult with AOSD and PAH in the literature.
\end{abstract}

Keywords: Adult onset Still's disease; Pulmonary hypertension; Young female adult; Yamaguchi criterions; Mycofenolate mofetil; Anakinra

\section{Introduction}

Adult onset Still's disease (AOSD) is a rare inflammatory syndrome mostly seen in young individuals, usually of ages between 15 and 36 years old [1]. Notably known for its wide range of clinical manifestations, Still's disease often presents itself by non-remitting systemic signs and symptoms: fever, arthralgia, leucocytosis, marked inflammatory profile, etc.

The diagnosis of AOSD is derived from the application of different sets of clinical diagnostic criteria [2-5]. The most widely used are those introduced by Yamaguchi [6] (Table 1). These criteria for the diagnostic of Still's disease have proved to have better sensitivity than others previously proposed, in an analysis by Masson et al [7]. Multiple laboratory

Manuscript accepted for publication March 21, 2013

${ }^{\mathrm{a}}$ Internal Medicine Service, Department of Medicine, Hotel-Dieu Hospital, University Hospital of Montreal (CHUM), 3840 St-Urbain street, Montreal, Quebec, Canada

${ }^{\mathrm{b}}$ Corresponding author: Mikhael Laskine, Hotel-Dieu Hospital, University Hospital of Montreal, 3840 St-Urbain street, Montreal, Quebec, H2V 2B3, Canada. Email: laskine1@gmail.com

doi: http://dx.doi.org/10.4021/jmc1202w tests also help for the diagnostic of AOSD. Although it is not exclusive to the disease, a highly elevated ferritin level is commonly associated with AOSD [8].

Other manifestations of the disease may consist in arthritis, pharyngitis, lymphadenopathy, organomegaly (especially liver and spleen), etc. Many rare case associations have been described with AOSD: pure red cell aplasia, disseminated intravascular coagulation, hemolytic anemia. However, although many rheumatologic diseases are associated with pulmonary arterial hypertension (PAH) (systemic sclerosis $[9,10]$, CREST syndrome, systemic lupus erythematous, Sjogren's syndrome [11], rheumatoid arthritis [12-14]), only a few reports have made a direct link between AOSD and PAH.

The following will present de case of AOSD associated with PAH.

\section{Case Report}

We present a case of a 36-year-old Vietnamese woman known for a 2-year course of an AOSD with frequent relapses treated with corticosteroids and an immunosuppressant agent (Mycophenolate Mofetil, Cellcept ${ }^{\circledR}$ ).

The diagnosis of AOSD was based on the presence of non-remitting systemic symptoms (fever, weight loss) and the presence of 3 major criteria (fever, arthralgia/arthritis, persistent leucocytosis) and 4 of the minor criteria (lymphadenopathy, hepato-splenomegaly, elevated serum hepatic aminotransferases and the absence on multiple occasions of ANA, anti-DNA or RF) from the Yamaguchi criterions [6]. She did not initially present a salmon-pink rash or a sore throat. The exclusion of multiple systemic, infectious and neoplastic syndromes had been done prior to the establishment of the diagnosis. Of note, the patient often presented levels of ferritin $>100,000 \mathrm{ng} / \mathrm{mL}$ during her relapses.

She presented herself at the emergency ward of our university teaching hospital in late 2008 for acute dyspnea.

The patient had been experiencing slight dyspnea on exertion for the past 3 - 4 months. She denied any infectious symptoms and had been compliant with her medication. Two to three days before her hospitalization, she gradually not- 
Table 1. Yamaguchi Criterion for Adult Onset Still's Disease*

\author{
Major criteria \\ Fever $\geq 39^{\circ} \mathrm{C}$, lasting $\geq 1$ week \\ Arthralgia, lasting $\geq 2$ weeks \\ Non-pruritic, salmon colored macular or maculopapular rash \\ Leukocytosis $\geq 10000 / \mu \mathrm{L}$, with $80 \%$ granulocytes \\ Minor criteria \\ Sore throat \\ Lymphadenopathy \\ Hepatomegaly or splenomegaly \\ Liver enzymes elevation \\ Negative ANA and RF**
}

* 5 criterions needed, with a minimum of 2 major; ${ }^{* *}$ ANA: Antinuclear antibody, RF: Rheumatoid factor.

ed an increase in her dyspnea without any other associated symptoms.

Her physical examination revealed a young woman with marked respiratory distress. The patient was tachypneic at a rate of $40 / \mathrm{min}$ and had a $\mathrm{SaO} 2$ of $80 \%$ on room oxygen. Oxygen via facemask was administered and her condition improved greatly. Empiric antibiotics were administered to treat what was thought to be pneumonia.

A ventilation-perfusion scintigraphy and a multibarret thoracic angioscan were performed to rule out a pulmonary embolism and were normal. There were no abnormalities upon reviewing the films. The lung parenchyma was normal. The heart did not display an abnormal left ventricle and pulmonary vessels were normal apart for a dilatation of the pulmonary arteries. To complete the investigation, a transthoracic cardiac sonography was performed. It revealed a normal left ventricle but a severely dilated right heart with a pulmonary artery hypertension, systolic reaching the 73 $\mathrm{mmHg}+\mathrm{CVP}$. Also noted was a severe tricuspid insufficiency. A year prior to this cardiac evaluation, the patient had undergone a cardiac sonography. Neither valve dysfunction nor elevated pulmonary artery pressure were noted at that time. The only abnormality was a small pericardial effusion without consequence on the ventricular dynamic.

Over the next few days, her condition stabilized and she was then referred to a specialized clinic of pulmonary artery hypertension. She was again evaluated for possible aetiologies related to her new pulmonary hypertension, but none were found. A repeat thoracic scan showed no abnormal parenchyma, only dilated pulmonary arteries; her right cardiac catheterization showed a pulmonary capillary wedge pressure (PCWP) of $13 \mathrm{mmHg}$ and a mean pulmonary artery pressure of 43 (normal $<25 \mathrm{mmHg}$ at rest [15-18]. A left cardiac catheterization demonstrated a left ventricular end diastolic pressure (LVEDP) of $15 \mathrm{mmHg}$. The patient's final diagnosis was a PAH associated with AOSD.

A treatment with Anakinra, Kineret $\AA$ had been started on her follow-up visits to try to prevent clinical worsening of her AOSD. She was also to begin treatment for her PAH. Unfortunately, the patient died of a septic shock a few weeks later. The family refused an autopsy.

\section{Discussion}

We have just portrayed a case of pulmonary artery hypertension (PAH) in the setting of an adult onset Still's disease (AOSD). Lack of evidence toward any other etiology makes us believe that this PAH was a direct consequence of Still's disease. Furthermore, the patient's PAH developed a few years after the beginning of her AOSD. It is improbable that the patient would be diagnosed with two very uncommon diseases without their being an association between the two pathologies. Thus, idiopathic pulmonary artery hypertension (iPAH) is, in our view, not a diagnosis to retain. As mentioned earlier, other causes (classification groups 2 through 5) $[15,19]$ of PAH had been excluded (Table 2).

No pulmonary venous hypertension was detected on cardiac echography and right heart catheterization showed a normal pulmonary artery occlusive pressure. There was no evidence of left heart dysfunction on the left cardiac catheterization. Multiple contrasts enhanced thoracic scans and pulmonary ventilation-perfusion scintigraphy did not denote the presence of a chronic or acute thromboembolic process. A schistosomiasis infection had also been excluded to rule out a possible Katayama syndrome [20] with a presentation 
Table 2. WHO Classification of Pulmonary Artery Hypertension (PAH)

Group 1 PAH: pulmonary arterial hypertension

Sporadic PAH

Familial PAH

PAH associated with small arteriolar diseases (collagen vascular disease, anorexigens, HIV, etc)

Group 2 PAH: pulmonary venous hypertension

Mainly left heart disease

Group 3 PAH: PAH associated with respiratory system disorder

Sleep apnea

Interstitial lung diseases

Chronic obstructive pulmonary disease

Group 4 PAH: PAH associated with thrombotic disorders

Thrombotic occlusion of pulmonary arteries (pulmonary embolisms)

Non-thrombotic occlusion of pulmonary arteries (Katayama disease seen with schistosomiasis)

Group 5 PAH: PAH of extrinsic nature

Mechanical compression of pulmonary vasculature (sarcoidosis, histiocytosis, etc)

of PAH [21-23]. No parenchymal abnormalities have been seen on all the thoracic scans and a nocturnal saturometry did not correlate with the presence of sleep apnea. No HIV infection or drug abuse was documented.

The diagnosis of group $1 \mathrm{PAH}$ is based on the absence of other known or common causes $[14,15]$. In group 1 , collagen tissue diseases are established causes of PAH, scleroderma being the most frequently cited. However, this association does not apply to AOSD. In actual medical literature, it is not a widely recognized etiology of PAH. This could probably be in part due to a weak incidence of both diseases [24]. Nonetheless, the association of both pathologies in the same patient must arouse suspicion as too whether it is only an uneventful situation or if there could be a direct causality between the two entities. In recent years, a few papers have made the case for this association [25-28]. Only five cases have now been described. This would be the sixth.

The pathologic hallmarks of idiopathic PAH are intimal thickening, media hypertrophy and plexiform lesions. Plexiform lesions are associated with a monoclonal proliferation of endothelial cells in the intralobular arteries of the lung and are associated to some extent with disease severity. On histological examinations, these lesions are also found in $\mathrm{PAH}$ associated with connective tissue diseases [29, 30]. Although many resemblances are found between $\mathrm{PAH}$ and $\mathrm{PAH}$ associated with connectivitis, the exact mechanisms of pulmonary artery hypertension in the later are not completely understood. Infiltration of macrophages and $\mathrm{T}$ lymphocytes has been observed in the perivascular space of patients with iPAH and PAH induced by scleroderma [31]. The inflammatory process thus induced with the release of cytokines and growth factors by these cells may contribute to the vascular remodeling seen in these patients. Furthermore, some reports advocate a role of autoimmunity in the pathologic genesis of PAH [32]. Cases of regression of PAH with treatment of the underlying inflammatory process gives more weight to this argument. However, inference of these histo-pathologic mechanisms to AOSD patient's needs to be addressed with further studies; the main of the scientific data on PAH associated with rheumatic disorders coming from lupus and scleroderma patients.

As for our patient, a treatment of Anakinra had been initiated because of worsening symptoms. A decrease in her inflammatory profile was seen within the first days of the therapy. Within a week, the ferritin level dropped from over 100,000 to nearly $6,000 \mathrm{ng} / \mathrm{mL}$. This is in line with some other reports showing a dramatic response to Anakinra within days of onset of therapy [33]. Other reports show that Anakinra can be effective in treatment-refractory Still's disease [34-36]. It would have been informative to observe the evolution of the PAH after a few weeks of treatment with this IL-1 antagonist. However, the patient died of septic shock shortly after the initiation of the Anakinra.

In conclusion, this patient presented a case of severe PAH in the setting of an adult onset Still's disease. To our knowledge, this is the sixth documented case of such an as- 
sociation. Further studies are needed to better understand the causality between the two entities. We need to better characterize the epidemiologic profile of patients with severe adult onset Still's disease to determine which patients are at risk of PAH. However, its infrequency may prove to be the major limitation in accomplishing this goal.

\section{Grant Support}

No grant support.

\section{Conflict of Interest}

No conflict of interest.

\section{References}

1. Ohta A, Yamaguchi M, Kaneoka H, Nagayoshi T, Hiida M. Adult Still's disease: review of 228 cases from the literature. J Rheumatol. 1987;14(6):1139-1146.

2. Calabro JJ, Marchesano JM. Fever associated with juvenile rheumatoid arthritis. N Engl J Med. 1967;276(1):1118.

3. Reginato AJ, Schumacher HR, Jr., Baker DG, O’Connor CR, Ferreiros J. Adult onset Still's disease: experience in 23 patients and literature review with emphasis on organ failure. Semin Arthritis Rheum. 1987;17(1):39-57.

4. Kahn MF, Delaire M. Maladie de Still de l'adulte. In: Kahn, MF, et al. eds, Les maladies systemiques. Paris 1991; Flammarion.

5. Goldman JA, Beard MR, Casey HL. Acute febrile juvenile rheumatoid arthritis in adults: cause of polyarthritis and fever. South Med J. 1980;73(5):555-563.

6. Yamaguchi M, Ohta A, Tsunematsu T, Kasukawa R, Mizushima Y, Kashiwagi H, Kashiwazaki S, et al. Preliminary criteria for classification of adult Still's disease. J Rheumatol. 1992;19(3):424-430.

7. Masson C, Le Loet X, Liote F, Dubost JJ, Boissier MC, Perroux-Goumy L, Bregeon C, et al. Comparative study of 6 types of criteria in adult Still's disease. J Rheumatol. 1996;23(3):495-497.

8. Morgan MA, Hoffbrand AV, Laulicht M, Luck W, Knowles S. Serum ferritin concentration in Gaucher's disease. Br Med J (Clin Res Ed). 1983;286(6381):1864.

9. Launay D, Humbert M, Hachulla E. [Pulmonary arterial hypertension and systemic sclerosis]. Presse Med. 2006;35(12 Pt 2):1929-1937.

10. Johnson SR, Patsios D, Hwang DM, Granton JT. Pulmonary veno-occlusive disease and scleroderma associated pulmonary hypertension. J Rheumatol. 2006;33(11):2347-2350.
11. Launay D, Hachulla E, Hatron PY, Jais X, Simonneau G, Humbert M. Pulmonary arterial hypertension: a rare complication of primary Sjogren syndrome: report of 9 new cases and review of the literature. Medicine (Baltimore). 2007;86(5):299-315.

12. Castro GW, Appenzeller S, Bertolo MB, Costallat LT. Isolated pulmonary hypertension secondary to rheumatoid arthritis. Clin Rheumatol. 2006;25(6):901-903.

13. Cottin V. Hypertension arterielle pulmonaire associee aux connectivites. Rev Mal Respir 2006 ; 23 : 13S61$13 \mathrm{~S} 72$.

14. Galie N, Manes A, Farahani KV, Pelino F, Palazzini M, Negro L, Romanazzi S, et al. Pulmonary arterial hypertension associated to connective tissue diseases. Lupus. 2005;14(9):713-717.

15. Barst RJ, McGoon M, Torbicki A, Sitbon O, Krowka MJ, Olschewski H, Gaine S. Diagnosis and differential assessment of pulmonary arterial hypertension. J Am Coll Cardiol. 2004;43(12 Suppl S):40S-47S.

16. Galie N, Torbicki A, Barst R, Dartevelle P, Haworth S, Higenbottam T, Olschewski H, et al. Guidelines on diagnosis and treatment of pulmonary arterial hypertension. The Task Force on Diagnosis and Treatment of Pulmonary Arterial Hypertension of the European Society of Cardiology. Eur Heart J. 2004;25(24):2243-2278.

17. Hatano S, Strasser T. World Health Organization 1975 primary pulmonary hypertension. Geneva : WHO ; 1975.

18. Rubin LJ. Diagnosis and management of pulmonary arterial hypertension: ACCP evidence-based clinical practice guidelines. Chest. 2004;126(1 Suppl):7S-10S.

19. Simonneau G, Galie N, Rubin LJ, Langleben D, Seeger W, Domenighetti G, Gibbs S, et al. Clinical classification of pulmonary hypertension. J Am Coll Cardiol. 2004;43(12 Suppl S):5S-12S.

20. Ross AG, Vickers D, Olds GR, Shah SM, McManus DP. Katayama syndrome. Lancet Infect Dis. 2007;7(3):218224.

21. Lapa M, Dias B, Jardim C, Fernandes CJ, Dourado PM, Figueiredo M, Farias A, et al. Cardiopulmonary manifestations of hepatosplenic schistosomiasis. Circulation. 2009;119(11):1518-1523.

22. Ramanampamonjy RM, Razafimahefa SH, Rajaonarivelo P, Rajaona HR. [Portopulmonary hypertension due to schistosomiasis in two Malagasy patients]. Bull Soc Pathol Exot. 2007;100(1):28-29.

23. de Cleva R, Herman P, Pugliese V, Zilberstein B, Saad WA, Rodrigues JJ, Laudanna AA. Prevalence of pulmonary hypertension in patients with hepatosplenic Mansonic schistosomiasis--prospective study. Hepatogastroenterology. 2003;50(54):2028-2030.

24. Magadur-Joly G, Billaud E, Barrier JH, Pennec YL, Masson C, Renou P, Prost A. Epidemiology of adult Still's disease: estimate of the incidence by a retrospective 
study in west France. Ann Rheum Dis. 1995;54(7):587590.

25. Mubashir E, Ahmed MM, Hayat S, Heldmann M, Berney SM. Pulmonary hypertension in a patient with adultonset Stills disease. Clin Rheumatol. 2007;26(8):13591361.

26. Chen $\mathrm{CH}$, Chen HA, Wang HP, Liao HT, Chou CT, Huang DF. Pulmonary arterial hypertension in autoimmune diseases: an analysis of 19 cases from a medical center in northern Taiwan. J Microbiol Immunol Infect. 2006;39(2):162-168.

27. Zen A, Yamashita N, Ueda M, Asakawa Y, Yoshikawa Y, Funai T, Hashimoto T. [A case of adult Still's disease with pulmonary hypertension]. Ryumachi. 1990;30(1):45-52.

28. Campos M, Schiopu E. Pulmonary Arterial Hypertension in Adult-Onset Still's Disease: Rapid Response to Anakinra. Case Rep Rheumatol. 2012;2012:537613.

29. Yokoi T, Tomita Y, Fukaya M, Ichihara S, Kakudo K, Takahashi Y. Pulmonary hypertension associated with systemic lupus erythematosus: predominantly thrombotic arteriopathy accompanied by plexiform lesions. Arch Pathol Lab Med. 1998;122(5):467-470.

30. Cool CD, Stewart JS, Werahera P, Miller GJ, Williams RL, Voelkel NF, Tuder RM. Three-dimensional reconstruction of pulmonary arteries in plexiform pulmonary hypertension using cell-specific markers. Evidence for a dynamic and heterogeneous process of pulmonary endo- thelial cell growth. Am J Pathol. 1999;155(2):411-419.

31. Cool CD, Kennedy D, Voelkel NF, Tuder RM. Pathogenesis and evolution of plexiform lesions in pulmonary hypertension associated with scleroderma and human immunodeficiency virus infection. Hum Pathol. 1997;28(4):434-442.

32. Nicolls MR, Taraseviciene-Stewart L, Rai PR, Badesch DB, Voelkel NF. Autoimmunity and pulmonary hypertension: a perspective. Eur Respir J. 2005;26(6):1110-1118.

33. Fitzgerald AA, Leclercq SA, Yan A, Homik JE, Dinarello CA. Rapid responses to anakinra in patients with refractory adult-onset Still's disease. Arthritis Rheum. 2005;52(6):1794-1803.

34. Kalliolias GD, Georgiou PE, Antonopoulos IA, Andonopoulos AP, Liossis SN. Anakinra treatment in patients with adult-onset Still's disease is fast, effective, safe and steroid sparing: experience from an uncontrolled trial. Ann Rheum Dis. 2007;66(6):842-843.

35. Kotter I, Wacker A, Koch S, Henes J, Richter C, Engel A, Gunaydin I, et al. Anakinra in patients with treatmentresistant adult-onset Still's disease: four case reports with serial cytokine measurements and a review of the literature. Semin Arthritis Rheum. 2007;37(3):189-197.

36. Vasques Godinho FM, Parreira Santos MJ, Canas da Silva J. Refractory adult onset Still's disease successfully treated with anakinra. Ann Rheum Dis. 2005;64(4):647648. 